\title{
MENINGKATKANKAN KETERAMPILAN CUCI TANGAN SISWA SD MENGGUNAKAN MEDIA AUDIO VISUAL DALAM UPAYA PENCEGAHAN DIARE
}

\author{
Maisye Nur Aisyah ${ }^{1}$ Suyanto $^{2}$ \\ 1.2 Politeknik Kesehatan Surakarta \\ Suyanto: Jurusan Keperawatan Politeknik Kesehatan Surakarta J1 Sutoyo Mojosongo \\ Kota Surakarta, E-mail: suyanto.mkes@gmail.com
}

\begin{abstract}
Abstrak
Pendahuluan. Penyakit diare merupakan gangguan Buang Air Besar (BAB) ditandai dengan BAB lebih dari 3 kali sehari dengan konsistensi tinja cair, dapat disertai dengan darah. Salah satu upaya yang dapat dilakukan untuk mencegah diare yaitu dengan memberikan pendidikan kesehatan cuci tangan menggunakan media audio visual terhadap keterampilan pencegahan diare khusunya pada siswa SD. Metode. Penelitian ini menggunakan jenis kuantitatif dan desain penelitian quasi eksperimen dengan metode pretest-posttest without control one group design. Besar sampel penelitian ini sebanyak 51 responden dihitung mengunakan metode purposive sampling. Hasil. Setelah dilakukan uji Wilcoxon, diperoleh nilai $\mathrm{p} 0,000(\mathrm{p}<0,05)$ sehingga dapat diartikan bahwa terdapat pengaruh pendidikan kesehatan cuci tangan dengan menggunakan media audio visual terhadap keterampilan pencegahan diare pada siswa SD. Kesimpulan. Terdapat pengaruh pendidikan kesehatan cuci tangan dengan menggunakan media audio visual terhadap keterampilan pencegahan diare pada siswa SD. Rekomendasi Guna menciptakan kebiasaan praktik cuci tangan untuk pencegahan diare maka perlu ditingkatkan keterampilannya dengan menggunakan bantuan audio visual.
\end{abstract}

Kata Kunci: Audio Visual, Cuci Tangan, Pencegahan Diare.

\begin{abstract}
Abstrack
Backgrounds. Diarrhea is a bowel disorder (BAB) characterized by defecation more than 3 times a day with the consistency of liquid stools, may be accompanied by blood. One of the efforts that can be done to prevent diarrhea is by providing health education on hand washing using audio-visual media on diarrhea prevention skills, especially for elementary school students. Method. This study uses a quantitative type and a quasiexperimental research design with the pretest-posttest method without control one group design. The sample size of this study was 51 respondents calculated using purposive sampling method. Results. After the Wilcoxon test, the p-value was $0.000(p<0.05)$ so that it could be interpreted that there was an effect of handwashing health education using audio-visual media on diarrhea prevention skills in elementary school students. Conclusion. There is an effect of hand washing health education using audio-visual media on diarrhea prevention skills in elementary school students. Recommendations In order to create a habit of hand washing practice for the prevention of diarrhea, it is necessary to improve skills using audio-visual aids.
\end{abstract}

Keywords: Audio Visual, Diarrhea Prevention, Hand Washing 


\section{PENDAHULUAN}

Penyakit diare merupakan gangguan Buang Air Besar (BAB) ditandai dengan BAB lebih dari 3 kali sehari dengan konsistensi tinja cair, dapat disertai dengan darah. Penyakit diare masih menjadi masalah global dengan derajat kesakitan dan kematian yang tinggi di berbagai negara terutama di negara berkembang, dan juga sebagai salah satu penyebab utama tingginya angka kesakitan dan kematian anak. Secara umum, diperkirakan lebih dari 10 juta anak berusia kurang dari 5 tahun meninggal setiap tahunnya dimana sekitar 20\% meninggal karena infeksi diare. (Mubarak, 2015).

Menurut penelitian yang telah dilakukan bahwa penyakit diare adalah penyebab tertinggi kematian balita di seluruh dunia. Setiap tahun penyakit diare membunuh sekitar 525.000 anak balita. Secara global, ada hampir 1,7 miliar kasus penyakit diare pada anak setiap tahunnya (WHO, 2017).

Berdasarkan hasil Riset Kesehatan Dasar tahun 2018 menemukan bahwa angka prevalensi di Indonesia untuk penyakit diare turun dari $18,5 \%$ menjadi $12,3 \%$ namun sampai sekarang penyakit diare masih menjadi masalah kesehatan di Indonesia karena morbiditas dan mortalitasnya masih terlalu tinggi. (Kementerian Kesehatan RI, 2018).
Provinsi Jawa Tengah memiliki kasus penyakit diare dari tahun 2017 sebesar 55,8\% yang mengalami penurunan dibanding tahun 2016 yaitu 68,9\% dan pada tahun 2015 sebesar 67,7\%. Sedangkan data Dinkes Kabupaten Klaten menunjukkan bahwa penyakit diare sampai saat ini masih masuk dalam 10 besar penyakit yang ada di Kabupaten Klaten, meskipun untuk tahun 2017 ini kasus penyakit diare pada semua umur mengalami penurunan apabila dibandingkan tahun 2016. Pada tahun 2017 kasus diare pada semua umur sebanyak 34.907 dan tahun 2016 sebanyak 36.660 kasus. Hal ini menunjukkan adanya penurunan 1753 kasus (Kementerian Kesehatan RI, 2017).

Secara prosentase jumlah penderita diare yang ditangani di Puskesmas mengalami penurunan dan kenaikkan. Hal tersebut dapat dilihatbpada data di Puskesmas Karangnongko. Berdasarkan hasil dari tahun 2017 turun sebesar 640 kasus dan tahun 2018 naik sebesar 1.202 kasus. Hal ini menunjukkan diare dari tahun 2016 mengalami penurunan dan kenaikan pada tahun 2018.

Faktor risiko diare, yang penularannya melalui vekal oral, terutama berhubungan dengan sarana air bersih, cara penyajian makanan, dan Pola Hidup Bersih dan Sehat 
(PHBS). Sehingga beberapa program untuk dapat melaksanakan PHBS di sekolah diajarkan berupa cara mencuci tangan, tidak jajan sembarangan, membuang sampah pada tempatnya, dan lain-lain.

Pelaksanaan PHBS di sekolah dapat dimulai dari hal yang paling kecil dan sederhana seperti mencuci tangan dengan sabun. Meningkatnya perilaku cuci tangan yang benar (cuci tangan dengan air yang mengalir dan sabun), setelah buang air besar, sebelum makan serta sebelum menyiapkan makanan menyebabkan perilaku ini bermanfaat untuk meningkatkan pencapaian derajat kesehatan (Purwandari, 2013).

Dengan memberikan praktik tentang cuci tangan diharapkan bisa mengurangi risiko terjadinya penularan penyakit melalui tangan dengan mencuci bersih. Makanan dan minuman yang dimasak dengan tangan kotor itu dapat menularkan penyakit (Wati, 2011).

Untuk meningkatkan keterampilan anak tentang penyakit diare, pihak sekolah belum pernah melakukan pendidikan kesehatan tentang penyakit diare dengan berbagai media, oleh karena itu peneliti tertarik untuk menggunakan audio visual sebagai media untuk pendidikan kesehatan.

\section{METODE}

Penelitian ini telah mendapatkan Surat Keterangan Layak Etik dari Komisi Etik Penelitian Kesehatan Poltekkes Surakarta No. LB.02.02/1.3/969/2020.

Jenis penelitian ini adalah penelitian kuantitatif komparatif dengan desain penelitian quasi eksperimen dengan metode pretestposttest without control group design yaitu untuk mengetahui keterampilan sebelum dan sesudah diberikan Pendidikan kesehatan tentang cuci tangan.

Sebagai populasi adalah seluruh siswa di SDN 2 Somokaton sedangkan sampel diambil dengan cara purposive sampling, sebanyak 51 siswa menggunakan kriteria inklusi: Siswa kelas 3 dan 4 yang pernah atau belum mengalami diare di SDN 2 Somokaton Karangnongko Klaten. Siswa yang hadir pada saat Pendidikan kesehatan. Sedangkan yang menjadi kriteria ekslusi: Tidak mengikuti penelitian sampai akhir. Responden tidak masuk atau dalam keadaan sakit saat intervensi dilakukan.

Media berupa video yang dibuat oleh peneliti ditayangkan dalam kelas disaksikan bersama sama selam 5 menit dan diulang sebanyak 2 kali dengan jeda selama 10 menit.

Untuk mengukur keterampilan menggunakan standar operasional prosedur cuci tangan 7 langkah. Instrumen yang 
digunakan berupa lembar observasi yang terdiri dari 12 kriteria dengan total skor sebanyak 24. Uji validitas

Instrumen penelitian yang digunakan berupa telah diuji validitas dan realibilitasnya oleh Asrita Ahmad tahun 2018 menggunakan uji Wilcoxon dengan tingkat signifikan $\mathrm{p}$ $=0,002$ atau $\mathrm{p}<0,05)$.

\section{HASIL}

Penelitian yang telah dilakukan di SD N 2 Jl. Somokaton, Kelurahan Somokaton, Karangnongko, Kabupaten Klaten, memperoleh data dan telah dianalisa sebagai berikut.

\section{Karakteristik responden penelitian}

Tabel 1 Distribusi frekuensi responden berdasarkan jenis kelamin, dan usia

\begin{tabular}{llll}
\hline Karakteristik & & $\mathrm{N}$ & $\%$ \\
\hline Jenis kelamin & Perempuan & 28 & 54,9 \\
& Laki-laki & 23 & 45,1 \\
Usia & 8 tahun & 6 & 11,8 \\
& 9 tahun & 19 & 37, \\
& 10 tahun & 26 & 51,
\end{tabular}

Berdasarkan tabel 1 dapat diketahui bahwa sebagian besar responden berjenis kelamin perempuan, yaitu berjumlah 28 siswa $(54,9 \%)$, dan usia maksimum responden yang mengikuti pendidikan kesehatan adalah 10 tahun yang berjumlah 26 siswa $(51,0 \%)$.

\section{Keterampilan Pencegahan Diare}

Tabel 2 Distribusi frekuensi keterampilan responden sebelum dan sesudah diberikan pendidikan kesehatan

\begin{tabular}{lllll}
\hline Kategori & \multicolumn{2}{l}{ Sebelum } & \multicolumn{2}{l}{ Sesudah } \\
\hline & $\mathrm{N}$ & $\%$ & $\mathrm{~N}$ & $\%$ \\
\hline Kurang & 47 & 92,1 & 0 & 0 \\
Cukup & 4 & 7,9 & 21 & 41,1 \\
Baik & 0 & 0 & 30 & 58,9 \\
\hline Total & 51 & 100 & 51 & 100 \\
\hline
\end{tabular}

Berdasarkan tabel 2 diketahui bahwa perilaku responden sebelum diberikan pendidikan kesehatan cuci tangan dengan menggunakan media audio visual terhadap keterampilan pencegahan diare, responden dengan kategori kurang sebanyak 47 siswa $(92,1 \%)$. Sedangkan perilaku responden setelah diberikan pendidikan kesehatan cuci tangan dengan menggunakan media audio visual terhadap keterampilan pencegahan diare, responden dengan kategori baik sebanyak 30 siswa $(58,9 \%)$.

Tabel 3 Analisa keterampilan responden sebelum dan sesudah diberikan pendidikan kesehatan

\begin{tabular}{llll}
\hline & N & Wilcoxon & P \\
\hline Sebelum & 51 & $-6,225$ & 0,000 \\
Sesudah & 51 & & \\
\hline
\end{tabular}

Berdasarkan tabel 3 diketahui bahwa nilai uji Wilcoxon adalah $-6,225$ dan $\mathrm{p}=0,000(\alpha=$ 0,05). Hasil ini menunjukan bahwa $\mathrm{p}<0,05$ 
maka Ho ditolak dan Ha diterima yang artinya ada pengaruh pendidikan kesehatan cuci tangan dengan menggunakan media audio visual terhadap keterampilan pencegahan diare pada siswa SD.

\section{PEMBAHASAN}

Pendidikan kesehatan yang dilakukan membentuk akan adannya proses interaksi antara peneliti dan responden untuk meningkatkan pengetahuan dalam pencegahan diare sehingga perubahan kebiasaan yang awalnya kurang baik dapat membaik. Hal tersebut dapat dimulai dengan melakukan cuci tangan. Cuci tangan merupakan cara yang paling sederhana untuk mencegah penularan infeksil dengan mereduksi jumlah bakteri pada tangan (Hertina, 2019)

Penelitian (Sari, 2016) mengungkapkan bahwa individu dalam intervensi pendidikan kesehatan membuktikan perbaikan yang lebih besar secara signifikan pada koping individu dalam pencegahan diare. Hal ini sejalan dengan penelitian (Sunardi \& Faqih R, 2017) yang telah menyatakan ada pengaruh perilaku cuci tangan berdampak pada insiden diare pada anak usia sekolah dengan dibuktikan hasil statistik yang menunjukkan nilai mean pretest sebesar 72,24 dan mean posttest sebesar 85,67.
Penyuluhan kesehatan bertujuan mengubah perilaku kurang sehat menjadi sehat yang artinya dapat mengubah pengetahuan responden yang kurang baik menjadi baik. Tujuan dari pemberian penyuluhan kesehatan adalah agar tercapainya perubahan perilaku individu, keluarga dan masyarakat dalam membina dan memlihara perilaku sehat dan lingkungan sehat, serta berperan aktif dalam upaya mewujudkan kesehatan yang optimal (Effendi N, 2012).

Media promosi kesehatan merupakan salah satu sarana yang digunakan untuk menampilkan pesan atau informasi yang ingin disampaikan kepasa siswa-siswi sehingga dapat meningkatkan pengetahuan yang akhirnya diharapkan dapat merubah perilakunya kearah yang lebih baik. Media video adalah media intraksional modern yang sesuai dengan perkembangan zaman meliputi media yang dapat dilihat dan didengar. Menggunakan bantuan video, pesan yang disampaikan lebih menarik pengetahuan dan motivasi bagi penonton (Lufianti, 2010). Pesan yang disampaikan lebih efisien karena gambar bergerak dapat mengkomunikasikan pesan dengan cepat dan nyata. Oleh karena itu, dapat mempercepat pemahaman pesan secara lebih komprehensif. Pesan audiovisual lebih efektif karena penyajian secara audio visual membuat 
penonton lebih memperhatikan (Hapsari, 2016).

Penyampaian materi pendidikan kesehatan pada penelitian ini dilakukan dengan media audio visual mengenai pencegahan diare. Saat dilakukan penyuluhan melalui media audio visual semua siswa antusias untuk memperhatikan materi pencegahan diare tersebut. Peneliti berasumsi bahwa yang menyebabkan perubahan keterampilan pada responden yaitu adanya media audio visual yang lebih berkesan serta mudah diingat.

Dengan adanya gambar animasi dengan suara dan gerakan dapat menarik perhatian siswa untuk lebih memperhatikan, dengan begitu dapat mendorong siswa untuk merubah perilaku menjadi lebih baik.

Hal ini sesuai dengan penelitian (Dita, 2015) yang yang mengemukakan bahwa terdapat pengaruh pendidikan kesehatan dengan metode audio visual, dikarenakan pesan yang disampaikan dapat diterima dengan baik. Artinya keberhasilan penyuluhan dipengaruhi oleh media karena media dapat mempengaruhi pengetahuan, sikap dan emosi.

Penelitian lain yang bertujuan ingin mengetahui pengaruh media audio visual terhadap pengetahuan dan sikap pada ibu hamil tentang pencegahan stunting di Desa Cinta Rakyat. Diperoleh hasil bahwa ada perbedaan yang signifikan antara pengetahuan dan sikap Ibu hamil sebelum dan sesudah intervensi menggunakan media audio visual (Anggraini, Sopyah A Siregar, 2020).

\section{KESIMPULAN}

Berdasarkan hasil penelitian terhadap 51 responden tentang pengaruh Pendidikan kesehatan cuci tangan dengan menggunakan media audio visual terhadap keterampilan pencegahan diare pada siswa SD dapat disimpulkan bahwa ketrampilan responden nampak meningkat dan tidak ditemukan ketrampilan kategori kurang setelah dilakukan pendidikan kesehatan.

Selanjutnya disimpulkan bahwa terdapat perbedaan yang signifikan anatara sebelum dan sesudah diberikan pendidikan kesehatan sehingga Ho ditolak dan Ha diterima atau ada pengaruh pendidikan kesehatan cuci tangan dengan menggunakan media audio visual terhadap keterampilan pencegahan diare pada siswa SD.

Sebagai saran yaitu diharapkan ketika memberikan keterampilan pada siswa dilakukan dengan bantuan audio visual agar ketrampilan siswa meningkat. Sedangkan bagi peneliti lain kiranya hasil penelitian ini dapat digunakan sebagai referensi untuk melakukan penelitian serupa dan diharapkan peneliti 
selanjutnya dapat menambahkan media lain sebagai pembanding media audio visual.

\section{UCAPAN TERIMA KASIH}

Terima kasih kepada pihak Politeknik Kesehatan Surakarta Jurusan Keperawatan dan SDN 2 Somokaton Karangnongko Klaten yang telah memfasilitasi dan berpartisipasi dalam penelitian ini.

\section{REFERENSI}

Anggraini, Sopyah A Siregar, S. D. (2020). Pengaruh Media Audio Visual Terhadap Tingkat Pengetahuan Dan Sikap Pada Ibu Hamil Tentang Pencegahan Stunting Di Desa Cinta Rakyat. Jurnal Ilmiah Kebidanan Imelda, 6. Retrieved from https://jurnal.uimedan.ac.id/index.php/Jur nalkebidanan/issue/view/37

Dita. (2015). Pengaruh Pendidikan kesehatan dengan metode Audio Visual Terhadap Pelaksanaan Cuci tangan pakai Sabun pada Anak Usia Prasekolah di TK Al Adaby Kota Pontianak. Jurnal Proners, vol 3. no. Retrieved from https://jurnal.untan.ac.id/index.php/jmkep erawatanFK/article/view/27106

Effendi N. (2012). Dasar-Dasar Keperawatan Kesehatan Masyarakat. Jakarta: EGC.

Hapsari. (2016). Psikologi Perkembangan Anak. Jakarta: PT Indeks.

Hertina. (2019). Pengaruh Cuci Tangan Terhadap Penurunan Jumlah Bakteri pada Hospital Personel di RS Nasional Diponegoro. Jurnal Kedokteran Diponegoro, 8 no.2, 841-851. Retrieved from

https://ejournal3.undip.ac.id/index.php/me dico/index

Kementerian Kesehatan RI. (2017). Profil Kesehatan Kabupaten Klaten Tahun 2017. Jakarta.

Kementerian Kesehatan RI. (2018). Riset Kesehatan Dasar. Jakarta. Retrieved from https://drive.google.com/file/d/1 Vpf3ntF Mm3A78S8Xlan2MHxbQhqyMV $5 \mathrm{i} /$ view.

Lufianti, A. (2010). Perbedaan pengaruh pembelajaran perawatan payudara (Breast Care) dengan Video Compact Disc (VCD) dibandingkan dengan phantom terhadap pengetahuan dan motivasi belajar pada mahasiswa DIII Keperawatan Sekolah Tinggi Ilmu Kesehatan An-Nur Purwodadi. Surakarta.

Mubarak, I. \& S. (2015). Buku Ajar Ilmu Keperawatan dasar. Jakarta: Salemba Medika.

Purwandari. (2013). Hubungan Antara Perilaku Cuci tangan dengan Insiden Diare pada Anak Usia Sekolah Di Kabupaten Jember. Jurnal Keperawatan, 4. Retrieved from https://ejournal.umm.ac.id/index.php/kepe rawatan/article/view/2362

Sari, - (2016). (2016). Pengaruh pendidikan Kesehatan tentang Cuci tangan melalui Media Ular tangga Terhadap Peningkatan Pengetahuan Anak usia Prasekolah di TK ABA Karang Bendo dan TK Pertiwi 21 babadan Bangun Tapan Bantul Yogyakarta. Yogyakarta.

Sunardi \& Faqih R. (2017). Perilaku Mencuci tangan berdampak Pada Insiden Diare Pada AnakUsia Sekolah di Kabupaten Malang. Jurnal Keperawatan, 8. 
Retrieved from

https://docplayer.info/47760983-Perilakumencuci-tangan-berdampak-pada-insidendiare-pada-anak-usia-sekolah-dikabupaten-malang.html

Wati. (2011). Pengaruh Pemberian Penyuluhan PHBS tentang Mencuci Tangan terhadap Pengetahuan dan Sikap Mencuci Tangan pada Siswa Kelas V di SDN Bulukantil Surakarta. Surakarta. Retrieved from https://eprints.uns.ac.id/6069/le

WHO. (2017). Inear healing at home. Jakarta: Gramedia. 